\title{
Redes Neurais Artificiais na estimação de variáveis biométricas de mudas de espécies florestais produzidas em diferentes substratos
}

\author{
Artificial Neural Networks for estimating the biometric variables of seedlings from forest species \\ produced in different substrates
}

Milton Marques Fernandes ${ }^{1 *}$, Francisco Luis Sousa ${ }^{2}$, Jeferson Pereira Martins Silva ${ }^{3}$, Emanuel França
Araújo $^{3}$, Márcia Rodrigues de Moura Fernandes ${ }^{3} \&$ Rafaela Simão Abrahão Nóbrega $^{4}$

${ }^{1}$ Universidade Federal de Sergipe, Aracajú, SE, Brasil. *Autor para correspondência: miltonmf@gmail.com.

${ }^{2}$ Universidade Federal do Piauí, Bom Jesus, PI, Brasil

${ }^{3}$ Universidade Federal do Espírito Santo, Jerônimo Monteiro, ES, Brasil.

${ }^{4}$ Universidade Federal do Recôncavo Baiano, Cruz das Almas, BA, Brasil.

Submissão:09/12/2017 / Aceite: 03/05/2018

\begin{abstract}
RESUMO
O objetivo do trabalho foi avaliar o crescimento em diâmetro do coleto e altura, e a produção de matéria seca total de mudas de Myracrodruon urundeuva, Jacaranda brasiliana e Mimosa caesalpiniaefolia. Concomitantemente, desenvolveu-se uma Rede Neural Artificial (RNA) do tipo Multilayer Perceptron que seria capaz de estimar a $\mathrm{H}$ e a MST das mudas das espécies estudadas. As mudas foram cultivadas em ambiente protegido com $50 \%$ de sombra. Assim, os tratamentos foram considerados com cinco proporções do material orgânico $(0,20,40,60$ e $80 \%$ v/v) na composição do substrato final (solo da área desertificada). Aos 120 dias após a semeadura, as mudas foram coletadas para determinação das variáveis biométricas. A rede MLP foi utilizada empregando-se o algoritmo de treinamento Levenberg-Marquardat. As variáveis utilizadas como entrada da MLP para a estimação da altura e massa seca das mudas foram: diâmetro do coleto, diâmetro mínimo, médio e máximo do coleto, as espécies e fontes de resíduos orgânicos (esterco bovino, esterco caprino e palha de arroz), totalizando dez entradas. Foi utilizada a função de ativação tangente hiperbólica. Como resultados, recomenda-se a proporção 80:20\% (esterco bovino e/ou esterco caprino:solo da área degradada) ao substrato de cultivo para o crescimento das mudas das espécies. A adição de doses de esterco bovino e esterco caprino influenciaram o DC do Jacaranda brasiliana, sendo constatado o efeito linear crescente com valor estimado de 2,66 mm planta ${ }^{-1}$. Para a $\mathrm{H}$ a adição de esterco bovino e caprino influenciou no crescimento das mudas de Myracrodruon urundeuva. A produção de MST das mudas das três espécies foi igualmente distribuída em função das proporções crescentes de resíduo orgânico incorporado ao substrato de cultivo. O uso da Rede Neural Artificial do tipo Multilayer Perceptron mostrou-se eficiente para a estimação da altura e da massa total seca das mudas das espécies estudadas.
\end{abstract}

PALAVRAS-CHAVE: recuperação de áreas degradadas, inteligência artificial, substratos orgânicos.

\begin{abstract}
The aim of this study was to evaluate the stem growth in diameter and height as well as the production of total dry matter from seedlings of Myracrodruon urundeuva, Jacaranda brasiliana and Mimosa caesalpiniaefolia. Concurrently, an Artificial Neural Network (RNA) of Multilayer Perceptron type that would be able to estimate the $\mathrm{H}$ and the MST of the seedlings of the studied species was developed. The seedlings were cultivated in a protected environment with $50 \%$ shade. Thus, the treatments were considered with five proportions of the organic material $(0,20,40,60$ and $80 \% \mathrm{v} / \mathrm{v}$ ) in the final substrate composition (desertified area soil). At 120 days after sowing, the seedlings were collected to determine the biometric variables. The MLP network was used with help of the Levenberg-Marquardat training algorithm. The variables used as input of the MLP for height and dry mass estimation of the seedlings were: stem diameter, minimum, medium and maximum diameter of stem; and species and sources of organic residues (cattle manure, goat manure and rice straw), totaling ten entries. The hyperbolic tangent activation function was conducted. As a result, a $80: 20 \%$ ratio (bovine manure and/or goat manure: soil from the degraded area) is recommended to be used in the growing substrate for seedling growth. The addition of bovine manure and goat manure doses influenced the Jacaranda brasiliana DC, with the linear effect increasing with the estimated value of 2.66 $\mathrm{mm}_{\text {plant }}{ }^{-1}$. For $\mathrm{H}$, the addition of bovine and goat manure influenced the growth of Myracrodruon urundeuva seedlings. The MST production of seedlings from the three species was also distributed as a function of the
\end{abstract}


increasing proportions of organic residues incorporated into the culture substrate. The use of the Artificial Neural Network of Multilayer Perceptron type was efficient for the estimation of the height and total dry mass of the species studied.

KEYWORDS: recovery of degraded areas, artificial intelligence, organic substrates.

\section{INTRODUÇÃO}

No nordeste do Brasil o desmatamento é devido principalmente ao constante avanço da expansão agropecuária na região do Cerrado-Caatinga. A demanda por informações silviculturais vem aumentando em relação às espécies florestais nativas, em razão do interesse no reflorestamento de áreas degradadas, matas ciliares e de áreas em processos de desertificação, comuns na região (LUSTOSA FILHO et al. 2015).

O sucesso desses programas é diretamente influenciado pela qualidade das operações de viveiro e do seu principal produto, as mudas. Nesta etapa, o substrato e a adubação são insumos estreitamente correlacionados que têm se destacado em importância devido à sua ampla influência na propagação de mudas. A utilização de resíduos orgânicos como fonte primária de nutrientes consiste em uma importante prática de gestão ambiental (BRASIL 2010), e uma alternativa ao uso de substratos comerciais e fertilizantes minerais, geralmente escassos e onerosos em regiões isoladas (ARAÚJO et al. 2017).

A avaliação da qualidade da muda geralmente é realizada por meio da análise de variáveis morfológicas e fisiológicas. O modelo de regressão polinomial simples é um dos métodos utilizados para investigar a relação entre a proporção ideal de material orgânico e o crescimento de mudas. O diâmetro de coleto (DC) e a altura $(\mathrm{H})$ são características morfológicas de fácil determinação amplamente utilizadas para classificação e seleção de mudas florestais em viveiro (CARNEIRO 1995, GOMES \& PAIVA 2012, LUSTOSA FILHO et al. 2015). Apresentam ainda, estreita relação com o potencial de sobrevivência e crescimento das mudas no campo (GASPARIN et al. 2014).

A massa seca é a variável mais consistente para descrever o crescimento e a qualidade das mudas florestais. Isso por que o crescimento vegetativo é o resultado da diferença entre ganhos em carbono via fotossíntese e as perdas via respiração (saldo do balanço de $\mathrm{CO}_{2}$ ), o carbono não consumido no processo respiratório aumenta a massa seca da planta (LARCHER 2000). Assim, quanto maiores forem os valores médios da massa seca das mudas, mais rustificada serão estas às condições de campo (CRUZ et al. 2006, CRUZ et al. 2011). Em contraste, por se tratar de uma variável determinada por um método destrutivo, demorado e dispendioso, sua mensuração e análise são inviáveis operacionalmente em muitos viveiros florestais comerciais.

O uso de uma variável de fácil mensuração como o DC para uma estimativa eficiente e segura da massa seca total (MST) de mudas florestais poderia vir ao encontro das dificuldades da mensuração desta variável, como a necessidade da destruição da muda e utilização de estufas de secagem.

Novas ferramentas de inteligência artificial, tais como, as RNA surgem no setor florestal como alternativa potencial em análise de dados, aumentando a precisão das estimativas e diminuindo os custos (LEITE et al. 2011).

O poder computacional da rede é extraída da sua estrutura paralela e distribuída, com isso, possui habilidade de aprender e generalizar o conhecimento adquirido, tornando-a capaz de solucionar problemas complexos (HAYKIN 2001, BRAGA et al. 2007, BINOTI et al. 2013). As RNA do tipo Multilayer Perceptron (MLP) são comumente utilizadas para aproximação de função.

A aplicação das RNA nas ciências florestais têm ganhado relevância por apresentar resultados de sucesso, como na área do manejo florestal (BINOTI et al. 2015), predição de incêndios florestais (MAEDA et al. 2009), ecologia florestal (CABACINHA \& LAFETÁ 2017), entre outros.

Este trabalho foi conduzido sob a hipótese de que maiores proporções de resíduos orgânicos na composição do substrato melhoram o crescimento de mudas florestais. Assim, o objetivo do trabalho foi avaliar o crescimento em DC e H, e a produção de MST de mudas de Myracrodruon urundeuva, Jacaranda brasiliana e Mimosa caesalpiniaefolia cultivadas em substratos com diferentes proporções de esterco bovino, esterco caprino e palha de arroz carbonizada. Paralelamente, um objetivo adicional deste estudo foi desenvolver uma RNA capaz de estimar a H e a MST das mudas das espécies estudadas.

\section{MATERIAL E MÉTODOS}

\section{Localização do experimento e produção das mudas}

O experimento foi realizado em casa de sombra, modelo "capela" (5,0 m de comprimento e 3,0 m de largura e pé direito 3,0 m e sombrite de 50\%), no Campus Profa. Cinobelina Elvas (CPCE) da Universidade 
Federal do Piauí (UFPI), em Bom Jesus, PI.

O município de Bom Jesus está situado nas coordenadas $09^{\circ} 04^{\prime} \mathrm{S}$ e $44^{\circ} 21^{\prime} \mathrm{W}$ com altitude média de 277 m. O clima da região é quente e semiúmido do tipo Aw (Köppen), com precipitação média de 900 a 1.200 $\mathrm{mm}$ ano-1 e duas estações bem definidas, a seca no período de maio a outubro e a chuvosa de novembro a abril (FERNANDES et al. 2014).

O delineamento inteiramente casualizado (DIC) em esquema fatorial $(3 \times 5)$ com dez repetições foi adotado, em que foram testadas as interações entre fontes de resíduos orgânicos e proporções de amostras de solo da área afetada pela desertificação no município de Gilbués, PI. As fontes de resíduos orgânicos utilizadas no experimento foram: esterco bovino (EB), esterco caprino (EC) e a palha de arroz (PA), todos adicionados em amostras de solo coletada na área desertificada. Assim, os tratamentos foram considerados como cinco proporções do material orgânico $(0,20,40,60$ e 80\%) na composição do substrato final (solo da área desertificada). Como recipiente foi utilizado tubetes plásticos com $110 \mathrm{~cm}^{3}$ de capacidade volumétrica. A caracterização química (Tabela 1) dos substratos foi realizada utilizando metodologia descrita por DONAGEMA et al. (2011).

Tabela 1. Caracterização química dos substratos compostos de diferentes proporções de material orgânico e solo de área desertificada para a produção de mudas.

Table 1. Chemical characterization of the substrates constituted by different proportions of organic material and desertified area soil for the production of seedlings.

\begin{tabular}{|c|c|c|c|c|c|c|c|c|c|}
\hline \multirow{2}{*}{\multicolumn{2}{|c|}{ Substratos }} & $\mathrm{pH}$ & $P$ & $\mathrm{~K}^{+}$ & $\mathrm{Ca}^{2+}$ & $\mathrm{Mg}^{2+}$ & $\mathrm{Al}^{3+}$ & $\mathrm{H}+\mathrm{Al}$ & \multirow{2}{*}{$\frac{\mathrm{MO}}{\text { dag kg}^{-1}}$} \\
\hline & & Água & \multicolumn{2}{|c|}{.......mg dm ${ }^{-3} .}$. & \multicolumn{4}{|c|}{$\ldots \ldots \ldots \ldots \ldots \ldots$ cmol dm${ }^{-3} \ldots \ldots \ldots \ldots \ldots$} & \\
\hline & $0-100$ & 7,1 & 12,2 & 121,0 & 15,5 & 4,1 & 0,0 & 1,9 & 1,3 \\
\hline & $20-80$ & 5,5 & 16,8 & 188,0 & 15,8 & 4,3 & 0,1 & 2,9 & 9,8 \\
\hline \multirow[t]{6}{*}{ EB } & $40-60$ & 4,6 & 15,5 & 188,5 & 10,5 & 9,0 & 0,2 & 4,0 & 17,9 \\
\hline & $60-40$ & 4,8 & 17,7 & 327,5 & 11,6 & 4,8 & 0,3 & 3,7 & 23,3 \\
\hline & $80-20$ & 4,1 & 36,9 & 94,4 & 13,9 & 6,5 & 0,9 & 5,9 & 31,7 \\
\hline & $20-80$ & 6,2 & 12,1 & 150,0 & 16,2 & 3,5 & 0,0 & 2,9 & 10,3 \\
\hline & $40-60$ & 6,0 & 16,2 & 170,1 & 16,5 & 5,3 & 0,0 & 2,5 & 21,9 \\
\hline & $60-40$ & 5,8 & 18,7 & 240,0 & 15,1 & 6,8 & 0,9 & 3,4 & 56,3 \\
\hline \multirow[t]{4}{*}{ EC } & $80-20$ & 5,5 & 39,7 & 245,3 & 12,5 & 9,7 & 0,7 & 3,8 & 96,6 \\
\hline & $20-80$ & 7,0 & 12,0 & 188,0 & 15,1 & 3,5 & 0,0 & 2,4 & 2,6 \\
\hline & $40-60$ & 7,1 & 13,5 & 375,1 & 14,7 & 2,2 & 0,0 & 2,0 & 9,8 \\
\hline & $60-40$ & 7,0 & 14,9 & 329,0 & 11,9 & 3,8 & 0,0 & 2,5 & 17,6 \\
\hline PA & $80-20$ & 7,0 & 17,9 & 92,9 & 7,3 & 3,7 & 0,0 & 2,3 & 30,3 \\
\hline
\end{tabular}

Em que: $\mathrm{EB}=$ esterco bovino; $\mathrm{EC}=$ esterco caprino; $\mathrm{PA}$ = palha de arroz.

As sementes das três espécies foram coletadas em dez diferentes matrizes localizadas no município de Gilbués. Aos 120 dias após a semeadura foram avaliadas as variáveis: diâmetro do coleto (DC), altura (H) e matéria seca total (MST). O DC foi medido com paquímetro de precisão de $0,05 \mathrm{~mm}$ e a altura com régua milimetrada, tomando-se como padrão a gema terminal (meristema apical). A massa seca foi avaliada por meio da pesagem das partes vegetais em balança de precisão digital, após a secagem em estufa a $65{ }^{\circ} \mathrm{C}$, por um período de aproximadamente $72 \mathrm{~h}$.

Os dados foram submetidos ao teste de verificação de pressuposição de normalidade (Shapiro-Wilk). Em seguida os dados foram submetidos à análise de variância e ao verificar diferenças significativas, pelo teste $F$ a $5 \%$, as médias foram submetidas à análise de regressão a fim de verificar a proporção de resíduo orgânico ótima para cada variável, por meio da primeira derivada dos estimadores $\beta_{0}$ e $\beta_{1}$. Para a escolha das equações foi considerada a significância dos modelos, o significado biológico e o coeficiente de determinação $\left(R^{2}\right)$. As análises foram realizadas utilizando-se o programa SISVAR 4.2.

\section{Processamento com RNA}

As RNA do tipo Multilayer Perceptron (MLP) são comumente utilizadas para aproximação de função, em razão disto, foram utilizadas neste estudo. Estas são compostas de camada de entrada, onde as variáveis são apresentadas à rede; camadas intermediárias ou ocultas, onde é feito o processamento, e a camada de saída, onde o resultado é apresentado (Figura 1). A camada intermediária é responsável por identificar os padrões não lineares dos dados com a utilização de funções de ativação, sendo comum as funções tangente hiperbólica e sigmoide (BRAGA et al. 2007). Neste estudo foi utilizada a função tangente hiperbólica na camada intermediária e a função linear na camada de saída. 


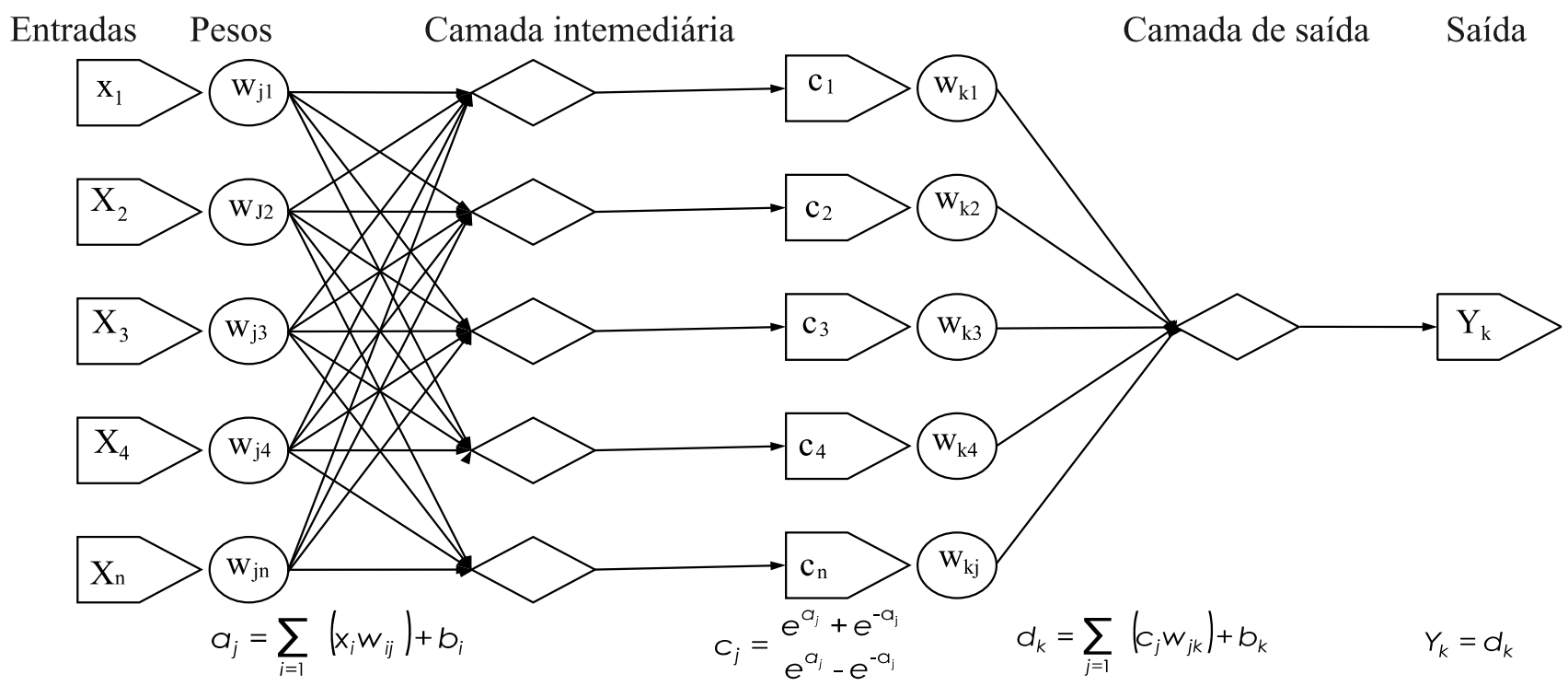

Figura 1. Rede neural artificial.

Figure 1. Artificial Neural Network.

Fonte: adaptado ASHRAF et al. (2015).

Para que se possa utilizar a rede MLP para estimar a altura e a massa seca total de mudas nativas é necessário o ajuste dos parâmetros da rede, que são os pesos sinápticos das conexões entre as unidades de processamento. Estes são ajustados em um processo iterativo comumente chamado de aprendizagem ou treinamento (BRAGA et al. 2007). O algoritmo de treinamento utilizado neste trabalho foi o LevenbergMarquardat. Tal algoritmo deixa o processo de convergência mais eficiente (SILVA et al. 2009).

As variáveis utilizadas como entrada das MLP para a estimação da $\mathrm{H}$ e MST das mudas foram: numéricas (diâmetro do coleto - DC, diâmetro do coleto mínimo - DCmin, diâmetro do coleto médio -DCmed, diâmetro do coleto máximo - Dcmax); e categóricas, as espécies Jacaranda brasiliana, Myracrodruon urundeuva e Mimosa caesalpiniaefolia e fontes de resíduos orgânicos (EB, EC e PA), totalizando dez entradas.

As entradas foram normalizadas em intervalos de -1 a 1, correspondente a função de ativação tangente hiperbólica. Depois de normalizadas as entradas foram inseridas na rede e passadas para a camada intermediária, em que a soma ponderada foi calculada de acordo com a Equação 1. O produto deste cálculo foi transmitido para as funções de ativação (tangente hiperbólica) (Equação 2). Os cálculos dos neurônios intermediários foram passados para frente e serviram de entrada para o neurônio de saída, descritas pelas Equações 3 e 4.

$$
\begin{aligned}
& a_{j}=\sum_{i=1}\left(x_{i} w_{i j}\right)+b_{i} \\
& C_{j}=\frac{e^{a_{j}}+e^{-a_{j}}}{e^{a_{j}}-e^{-a_{j}}} \\
& d_{k}=\sum_{j=1}\left(c_{j} w_{j k}\right)+b_{k} \\
& Y_{K}=d_{k}
\end{aligned}
$$

Para avaliação das estimativas geradas pelas RNA, para ajuste e validação, foram obtidas as estatísticas de coeficiente de correlação (r), viés e Raiz Quadrada do Erro Médio (RQME) (Tabela 2). 
Tabela 2. Estatísticas utilizadas para avaliar o desempenho das RNA na estimação da H e MST das mudas das espécies estudadas.

Table 2. Statistics used to evaluate RNA performance in the estimation of $H$ and MST of the species studied.

\begin{tabular}{ll}
\hline Estatísticas & Fórmulas \\
\hline Coeficiente de correlação & $r_{y \hat{y}}=\frac{\sum_{i=1}^{n}\left(Y_{i}-\bar{Y}\right)\left(\hat{Y}_{i}-\hat{Y}_{m}\right)}{\sqrt{\left[\sum_{i=1}^{n}\left(Y_{i}-\bar{Y}\right)^{2}\right]\left[\sum_{i=1}^{n}\left(\hat{Y}_{i}-\hat{Y}_{m}\right)^{2}\right]}}$ \\
Viés & № \\
Raiz quadrada do erro médio & $R=\frac{\sum_{i=1}^{n} Y_{i}-\sum_{i=1}^{n} \hat{Y}_{i}}{n}$
\end{tabular}

Em que: $Y_{i}=$ variável dependente observada, $\hat{Y}_{i}=$ variável dependente estimada, $\bar{Y}=$ média da variável dependente observada, $\hat{Y}_{m}=$ média da variável dependente estimada e $\boldsymbol{n}=$ número de observações.

Para complementar a avaliação, foi realizada a análise gráfica entre os dados observados e estimados e distribuição dos resíduos percentuais. $O$ erro de cada observação foi calculado em porcentagem, conforme equação 8.

$$
E_{i}(\%)=100 \cdot \frac{Y_{i}-\hat{Y}_{i}}{Y_{i}}
$$

Em que: $E_{i}(\%)=$ erro de cada observação.

\section{RESULTADOS E DISCUSSÃO}

\section{Crescimento das mudas}

Os resultados da análise de variância mostraram diferenças significativas entre as fontes de resíduos orgânicos e as proporções destes utilizadas como substratos e sua interação sobre as variáveis de crescimento das mudas das espécies estudadas (Tabela 3).

Tabela 3. Resumo da análise de variância para produção de mudas de Jacaranda brasiliana, Myracrodruon urundeuva e Mimosa caesalpiniaefolia cultivada em diferentes proporções de resíduos orgânicos e de solo da área desertificada de Gilbués, PI.

Table 3. Summary of analysis of variance for production of Jacaranda brasiliana, Myracrodruon urundeuva and Mimosa caesalpiniaefolia seedlings grown in different proportions of organic and soil residues from the desertified area of Gilbués, PI.

\begin{tabular}{|c|c|c|c|c|c|c|c|c|c|}
\hline \multirow[b]{2}{*}{$\begin{array}{l}\text { Fontes de } \\
\text { variação }\end{array}$} & \multicolumn{8}{|c|}{ Quadrados Médios } & Mimosa caesalpiniaefolia \\
\hline & $\mathrm{H}$ & $\mathrm{DC}$ & MST & $\mathrm{H}$ & $\mathrm{DC}$ & MST & $\mathrm{H}$ & DC & MST \\
\hline & $\mathrm{cm}$ & $\mathrm{mm}$ & $g$ & $\mathrm{Cm}$ & $\mathrm{mm}$ & $g$ & $\mathrm{~cm}$ & $\mathrm{~mm}$ & g \\
\hline Resíduos & $\overline{561,59^{*}}$ & $4,11^{*}$ & $4,99^{*}$ & $386,87^{*}$ & $8,41^{*}$ & $6,01^{*}$ & $851,41^{*}$ & $0,43^{*}$ & $2,31^{*}$ \\
\hline Proporção & 200,40 * & $1,12^{*}$ & $3,13^{*}$ & $154,96^{*}$ & $1,30^{*}$ & $1,86^{*}$ & $333,03^{*}$ & $1,51^{*}$ & $1,24^{*}$ \\
\hline$R \times P$ & $60,10^{*}$ & $0,35^{*}$ & $1,06^{*}$ & $38,79^{*}$ & $0,72^{*}$ & $0,58^{*}$ & $70,20^{*}$ & $0,09^{\text {ns }}$ & $0,32^{*}$ \\
\hline
\end{tabular}

Em que: $\mathrm{H}=$ Altura da parte aérea; $\mathrm{DC}$ = diâmetro do coleto; $\mathrm{MST}$ = massa seca total; *significativo a $5 \%$ de probabilidade pelo teste $\mathrm{F}$; $\mathrm{R}=$ resíduo; $\mathrm{P}=$ proporção; ${ }^{\text {ns }}$ não significativo a $5 \%$ de probabilidade.

A interação $(p<0,05)$ entre os fatores para o DC, H e MST das mudas Jacaranda brasiliana e Myracrodruon urundeuva apresentou dependência entre esses fatores na expressão dessa característica. $\mathrm{Na}$ Mimosa caesalpiniaefolia observou-se interação não significativa $(p<0,05)$ para o DC, indica que os fatores 
(fontes de resíduos orgânicos e proporções) agem isoladamente sobre essa variável.

A adição de doses de esterco bovino e esterco caprino influenciaram o DC das mudas de Jacaranda brasiliana, sendo constatado o efeito linear crescente (Figura 2a). O maior valor estimado (2,66 mm planta-1) para esta variável foi observado na proporção 80:20\% (esterco caprino:solo). As mudas cultivadas com a proporção $80: 20 \%$ (esterco bovino:solo) obtiveram média de $2,53 \mathrm{~mm}_{\text {planta-1}}{ }^{-1}$.

O DC das mudas de Myracrodruon urundeuva também foi influenciado pela adição de doses de esterco bovino e esterco caprino, sendo constatado o efeito linear crescente e quadrático, respectivamente, no entanto, os parâmetros das equações linear e quadrática não foram significativos (Figura 2b). Já as mudas de Jacaranda brasiliana e Myracrodruon urundeuva cultivadas com palha de arroz carbonizada não diferiram entre si $(p>0,05)$.
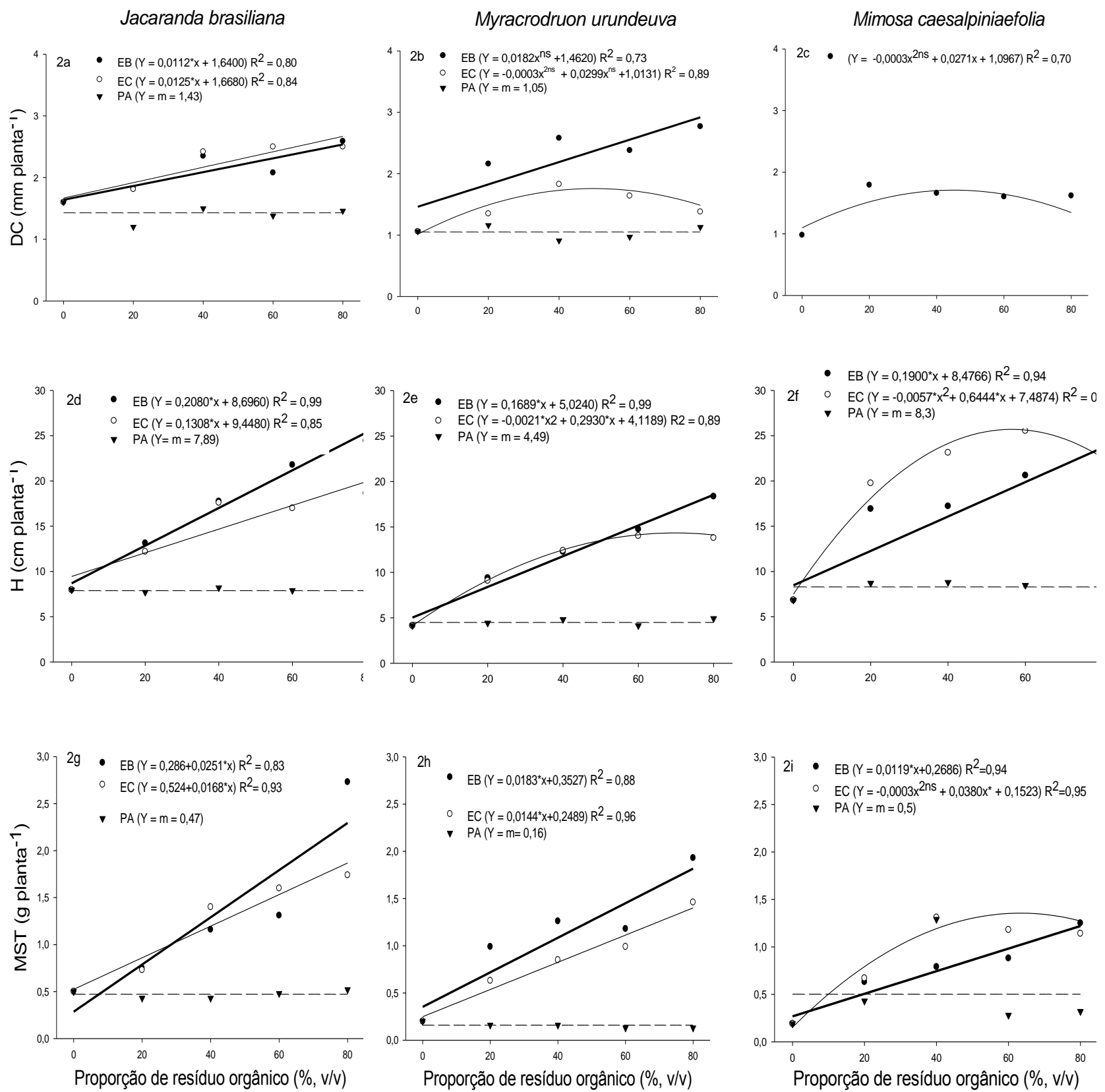

Figura 2. Diâmetro do coleto (DC), altura da parte aérea $(H)$ e matéria seca total (MST) de mudas de Jacaranda brasiliana, Myracrodruon urundeuva e Mimosa caesalpiniaefolia cultivada em solo da área desertificada de Gilbués, PI com diferentes proporções de resíduos orgânicos: esterco bovino (EB), esterco caprino (EC) e palha de arroz (PA).

Figure 2. Stem diameter (SD), aerial part height $(H)$ and total dry matter (TDM) Jacaranda brasiliana, Myracrodruon urundeuva and Mimosa caesalpiniaefolia seedlings grown in the desertified area of Gilbués, PI, with different residue ratios: cattle manure (CM), goat manure (GM) and rice straw (ST). 
Para o DC das mudas de Mimosa caesalpiniaefolia houve apenas efeito individual $(p<0,05)$ para as fontes de resíduos orgânicos utilizados, dentre os quais o esterco bovino e esterco caprino obtiveram maiores médias $1,61 \mathrm{~mm}_{\text {planta-1 e }} 1,60 \mathrm{~mm}$ planta $^{-1}$, respectivamente, não diferindo entre si. O crescimento em DC das mudas com palha de arroz apresentou média de $0,38 \mathrm{~mm}_{\text {planta-1}}{ }^{-1}$. Verificou-se também efeito individual quadrático $(p<0,05)$ entre as doses de resíduo orgânico, todavia, os parâmetros da equação quadrática não foram significativos (Figura 2c).

Em relação a $\mathrm{H}$ das mudas de Jacaranda brasiliana foi observada tendência de crescimento linear crescente para os resíduos orgânicos: esterco bovino e esterco caprino. $\mathrm{O}$ valor máximo estimado para $\mathrm{H}$ (24,33 $\mathrm{cm}$ planta $^{-1}$ ) foi obtido com a proporção 80:20\% (esterco bovino:solo) (Figura 2d).

A adição de esterco bovino e caprino na composição do substrato influenciou a $\mathrm{H}$ das mudas de Myracrodruon urundeuva. Foi observado crescimento linear crescente para o esterco bovino e quadrático para o esterco caprino (Figura 2e). As mudas cultivadas com a proporção 80:20\% (esterco bovino:solo) foram as mudas que obtiveram maiores médias $\left(18,36 \mathrm{~cm}\right.$ planta $\left.^{-1}\right)$. Para o esterco caprino, a proporção 69,7:30,3\% possibilitou o maior incremento na variável $\mathrm{H}\left(14,33 \mathrm{~cm}_{\text {planta-1}}{ }^{-1}\right)$.

A adição de doses de esterco bovino e esterco caprino para compor o substrato influenciaram a $\mathrm{H}$ das mudas de Mimosa caesalpiniaefolia com efeito linear crescente e efeito quadrático, respectivamente. As mudas cultivadas na proporção 80:20\% (esterco bovino:solo) obtiveram o valor máximo de $\mathrm{H}$ de $25,70 \mathrm{~cm}$ planta- $^{-1}$, enquanto que as mudas cultivadas com a proporção estimada 56,52:43,48\% (esterco caprino:solo) foram as que obtiveram maiores médias $\left(25,70 \mathrm{~cm}\right.$ planta $\left.^{-1}\right)$.

No que se refere aos tratamentos com palha de arroz o crescimento em $\mathrm{H}$ das mudas de Jacaranda brasiliana, Myracrodruon urundeuva e Mimosa caesalpiniaefolia seguiu a mesma tendência apresentada para o crescimento em DC, em que não foi apresentado efeito significativo ( $p>0,05)$.

A produção de MST das mudas de Jacaranda brasiliana e Myracrodruon urundeuva foram influenciadas de forma linear pela adição de esterco bovino e esterco caprino, em que o ponto máximo de produção, 2,73 e 1,79 $\mathrm{g} \mathrm{planta}^{-1}$ foram alcançados, respectivamente, na proporção $80: 20 \%$ (esterco bovino:solo). As mudas cultivadas com a proporção $80: 20 \%$ de esterco caprino e solo obtiveram médias de 1,83 g planta-1 para o Jacaranda brasiliana e 1,39 $\mathrm{g}_{\text {planta- }}$ para $^{-1}$ Myracrodruon urundeuva (Figura $2 \mathrm{~g}$ e Figura $2 \mathrm{~h}$ ).

Constatou-se que a MST das mudas de Mimosa caesalpiniaefolia foi influenciada pela adição de doses de esterco bovino e esterco caprino, com efeito linear crescente e quadrático, respectivamente. Para essa espécie, o esterco caprino foi o resíduo orgânico que proporcionou a produção de MST (1,36 g planta-1), obtida na proporção estimada 63,33:36,67\%. As mudas cultivadas nos tratamentos com esterco bovino apresentaram produção de $1,22 \mathrm{~g}$ planta- $^{-1}$, na proporção $80: 20 \%$.

A produção de MST das mudas das três espécies foi igualmente distribuída em função das proporções crescentes de resíduo orgânico incorporado ao substrato de cultivo, no qual os tratamentos com esse material não proporcionou diferença significativa $(p>0,05)$.

A hipótese de que as maiores proporções de resíduos orgânicos na composição de substratos aumentam o crescimento das mudas florestais testadas foi parcialmente confirmada. Observou-se que dentre os materiais testados, o esterco bovino e esterco caprino na proporção máxima de $80: 20 \%$ são os mais recomendados para o cultivo de mudas de Jacaranda brasiliana, Myracrodruon urundeuva e Mimosa caesalpiniaefolia.

De modo geral, o melhor resultado das variáveis biométricas das mudas nos substratos com maiores proporções destes resíduos podem estar relacionado ao aumento da fertilidade (Tabela 1), por meio do qual indica que essas espécies são bastante responsivas a adição de materiais orgânicos ao substrato.

Além disso, a incorporação desses materiais promovem melhorias nas propriedades físicas como diminuição da densidade e aumento da porosidade dos substratos, conforme destacado na literatura por ARAÚJO et al. (2017), que constataram que proporções crescentes de composto orgânico (80:20\%, composto:solo) contribuíram para melhor crescimento de mudas de Schizolobium amazonicum, sendo que a bagana de carnaúba, resíduo orgânico abundante no estado Piauí, promoveu melhor crescimento de mudas na proporção 53:47\% (bagana:solo).

$\mathrm{Na}$ avaliação da biometria, peso, facilidade de transporte de mudas e crescimento em campo de mudas de três espécies da Floresta Atlântica submetidas a diferentes proporções de biossólido como componente de substratos, CABREIRA et al. (2017) constataram que o uso do biossólido pode promover maior crescimento das mudas em viveiro, bem como diminuir o peso final das mesmas, facilitando a logística de expedição para o campo. Sendo indicada a aplicação entre 40 a 80\% de biossólido na composição do substrato. Resultados semelhantes foram encontrados no presente estudo, diferindo somente em relação aos resíduos orgânicos. 


\section{Redes Neurais Artificiais na estimativa da altura e massa seca total das mudas}

As estatísticas de $r$, RQME e viés para os conjuntos de treinamento e validação utilizadas nas $M L P$ para estimar H e MST estão apresentadas na Tabela 4 e Tabela 5, respectivamente. As estatísticas estão de acordo com a variação do número de neurônios utilizados (3 a 15). As variações destas estatísticas em função do número de neurônio na camada intermediária estão ilustradas também na Figura 3.

Tabela 4. Estatísticas para o conjunto de treinamento e validação das MLP para estimar altura de mudas de Jacaranda brasiliana, Myracrodruon urundeuva e Mimosa caesalpiniaefolia, com diferentes números de nós na camada intermediária.

Table 4. Statistics for the training set and validation of MLP to estimate height of Jacaranda brasiliana, Myracrodruon urundeuva and Mimosa caesalpiniaefolia seedlings, with different numbers of nodes in the middle layer.

\begin{tabular}{|c|c|c|c|c|c|c|}
\hline \multirow{2}{*}{$N^{\circ}$ neurônios } & \multicolumn{3}{|c|}{ Treino } & \multicolumn{3}{|c|}{ Validação } \\
\hline & $r$ & RQME & Viés & $r$ & RQME & Viés \\
\hline 3 & 0,9284 & 2,3894 & 0,1050 & 0,8895 & 3,0900 & 0,4200 \\
\hline 4 & 0,9757 & 1,5281 & 0,0000 & 0,9224 & 2,0196 & $-0,2738$ \\
\hline 5 & 0,9222 & 2,5350 & $-0,0875$ & 0,9250 & 2,7084 & $-1,3189$ \\
\hline 6 & 0,9406 & 2,1327 & 0,0899 & 0,9193 & 2,6321 & $-0,1292$ \\
\hline 7 & 0,9781 & 1,3699 & 0,1067 & 0,8363 & 3,6133 & 1,4168 \\
\hline 8 & 0,9677 & 1,4733 & 0,0213 & 0,8851 & 3,7512 & 1,4141 \\
\hline 9 & 0,9641 & 1,5954 & 0,4743 & 0,8419 & 4,7239 & 2,4323 \\
\hline 10 & 0,9677 & 1,8420 & 0,4404 & 0,8453 & 4,9911 & 2,6378 \\
\hline 11 & 0,9060 & 3,0413 & $-1,6700$ & 0,8412 & 4,0415 & $-0,3644$ \\
\hline 12 & 0,9771 & 1,4320 & 0,1658 & 0,7743 & 4,6167 & 2,3440 \\
\hline 13 & 0,8358 & 3,6297 & $-0,4269$ & 0,5261 & 5,4256 & 0,1257 \\
\hline 14 & 0,9750 & 1,2570 & $-0,0119$ & 0,6809 & 5,1988 & $-0,5592$ \\
\hline 15 & 0,7418 & 4,7872 & $-0,5351$ & 0,7232 & 5,9599 & $-0,8362$ \\
\hline
\end{tabular}

Em que: $r$ = coeficiente de correlação; RQME = Raiz Quadrada do Erro Médio calculados para o conjunto de treinamento e validação.

Tabela 5. Estatísticas para o conjunto de treinamento e validação das $M L P$ para massa seca total de mudas de Jacaranda brasiliana, Myracrodruon urundeuva e Mimosa caesalpiniaefolia, com diferentes números de nós na camada intermediária.

Table 5. Statistics for the training set and validation of MLP for total dry mass of Jacaranda brasiliana, Myracrodruon urundeuva and Mimosa caesalpiniaefolia seedlings, with different numbers of nodes in the middle layer.

\begin{tabular}{|c|c|c|c|c|c|c|}
\hline \multirow{2}{*}{$N^{\circ}$ neurônios } & \multicolumn{3}{|c|}{ Treino } & \multicolumn{3}{|c|}{ Validação } \\
\hline & $r$ & RQME & Viés & $r$ & RQME & Viés \\
\hline 3 & 0,9658 & 0,1686 & 0,0096 & 0,7964 & 0,3072 & $-0,0054$ \\
\hline 4 & 0,9229 & 0,2542 & 0,0320 & 0,7363 & 0,3423 & $-0,0603$ \\
\hline 5 & 0,9112 & 0,2371 & 0,0013 & 0,7614 & 0,3496 & $-0,0842$ \\
\hline 6 & 0,8781 & 0,2384 & 0,0064 & 0,7963 & 0,4462 & 0,0251 \\
\hline 7 & 0,7585 & 0,3354 & 0,0807 & 0,6589 & 0,5572 & 0,1137 \\
\hline 8 & 0,8784 & 0,3163 & $-0,0542$ & 0,9181 & 0,1816 & 0,0465 \\
\hline 9 & 0,9606 & 0,1639 & $-0,0025$ & 0,7804 & 0,3828 & 0,1354 \\
\hline 10 & 0,9238 & 0,2340 & $-0,0062$ & 0,9133 & 0,2114 & 0,0035 \\
\hline 11 & 0,9171 & 0,2498 & 0,0051 & 0,9067 & 0,2052 & $-0,0440$ \\
\hline 12 & 0,8991 & 0,2011 & 0,0115 & 0,8102 & 0,4512 & 0,1030 \\
\hline 13 & 0,9237 & 0,2345 & 0,0312 & 0,6468 & 0,3654 & 0,0783 \\
\hline 14 & 0,8177 & 0,3406 & $-0,0637$ & 0,3532 & 0,9114 & 0,2644 \\
\hline 15 & 0,9293 & 0,1918 & 0,0636 & 0,2736 & 0,7993 & $-0,1269$ \\
\hline
\end{tabular}

Em que: $r$ = coeficiente de correlação; RQME = Raiz Quadrada do Erro Médio calculados para o conjunto de treinamento e validação. 
As configurações das $M L P$ com as variações de neurônios na camada intermediária para estimar a altura total das plantas geraram para o conjunto de treinamento valores de $r$ entre 0,7418 e 0,9781 ; RQME de 1,2570 a 4,7872 e Viés de -1,658 a 0,4743 (Tabela 4).

No conjunto de dados de validação utilizados nas $M L P$ para verificar a capacidade de generalização, os valores de $r$ variaram entre 0,9250 e 0,5261; RQME de 2,6133 a 5,9599 e Viés de -1,3189 a 2,6378. Observa-se que para este mesmo conjunto de dados os valores de $r$ diminuem com aumento no número de neurônios a partir de sete neurônios na camada intermediária, mas foram semelhantes quando se considera de três a seis neurônios (Figura 3c).

Os valores mais baixos de RQME foram observados para MLP com quatro, cinco e seis neurônios e apresentou um aumento a partir de sete neurônios (Figura 3a). Os valores de Viés foram consistentes, mais baixos e próximos de zero para a MLP com quatro neurônios no conjunto de treinamento e 13 neurônios no conjunto de validação.
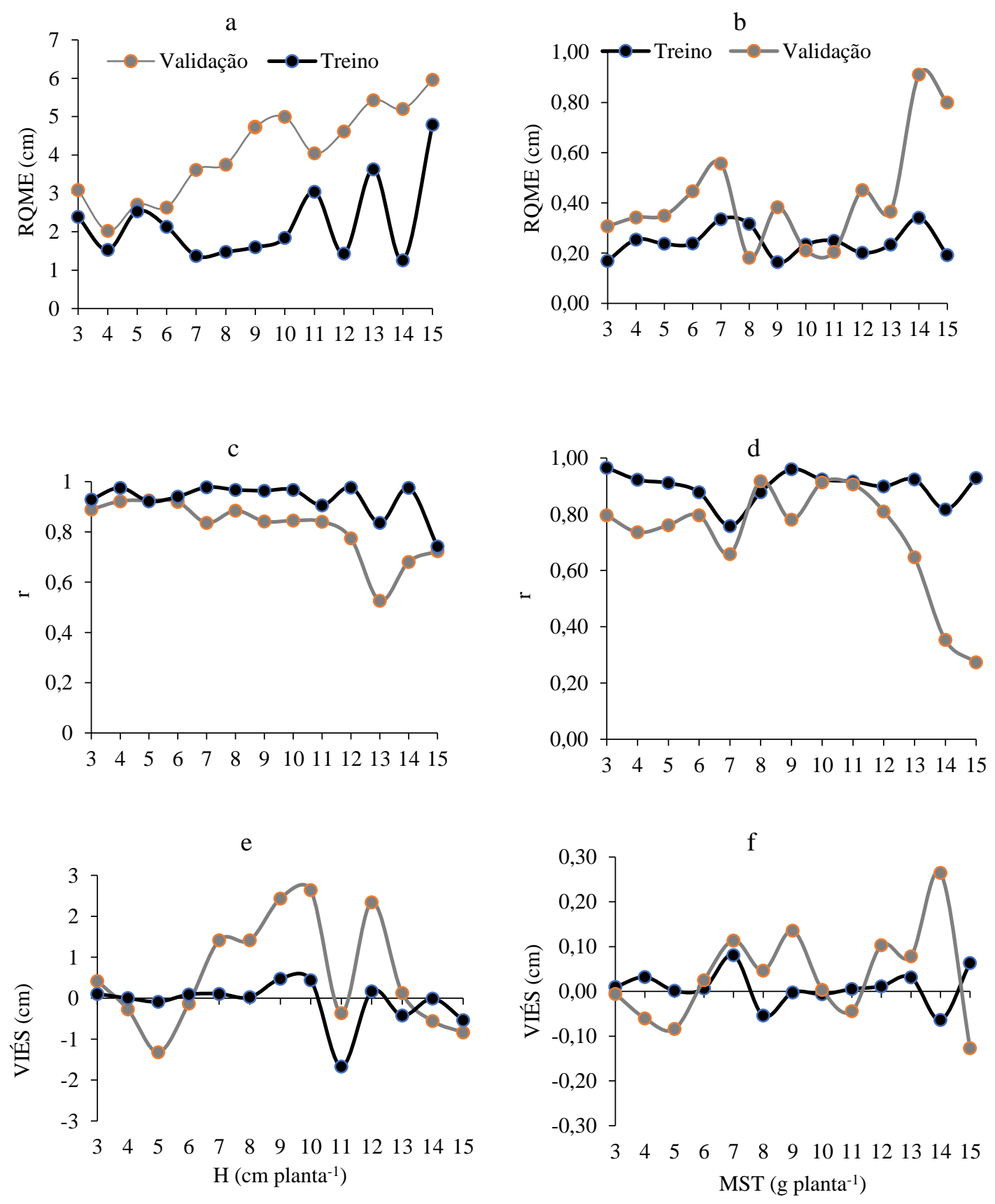

Figura 3. Tendência das estatísticas RQME, $r$ e viés para o conjunto de treinamento e validação em função do número de neurônios da camada intermediária para estimar altura (HT) e massa seca total (MST) de mudas de Jacaranda brasiliana, Myracrodruon urundeuva e Mimosa caesalpiniaefolia.

Figure 3. Trend for RQME, $r$ and bias statistics for the training set and validation as a function of the number of neurons from the intermediate layer to estimate height $(H)$ and total dry mass (TDM) of Jacaranda brasiliana, Myracrodruon urundeuva and Mimosa caesalpiniaefolia. 
$\mathrm{H}$

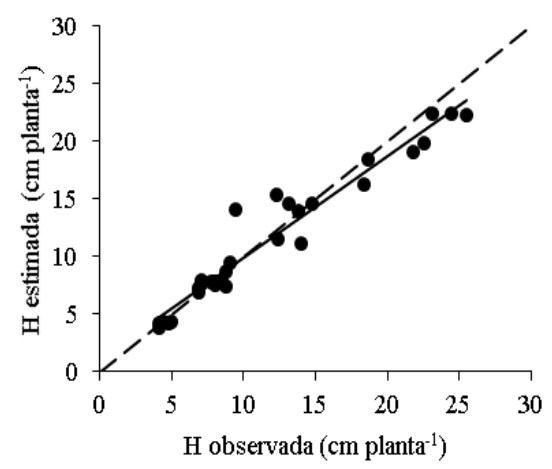

$\mathrm{H}$

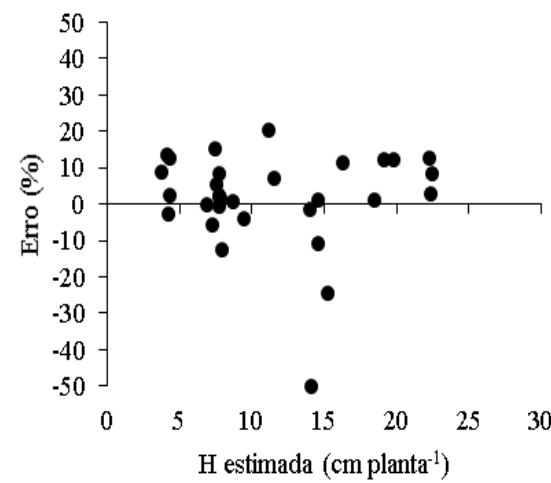

MST

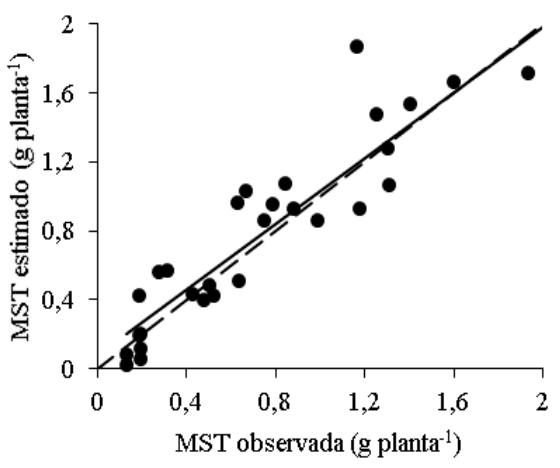

MST

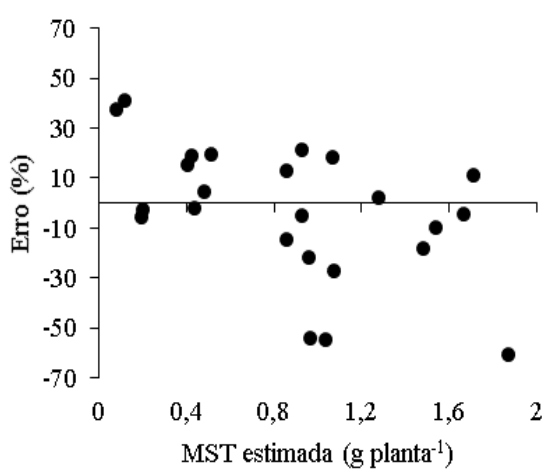

$\mathrm{H}$

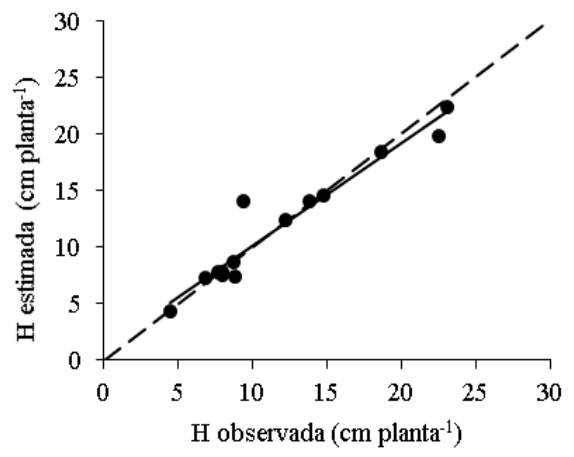

$\mathrm{H}$

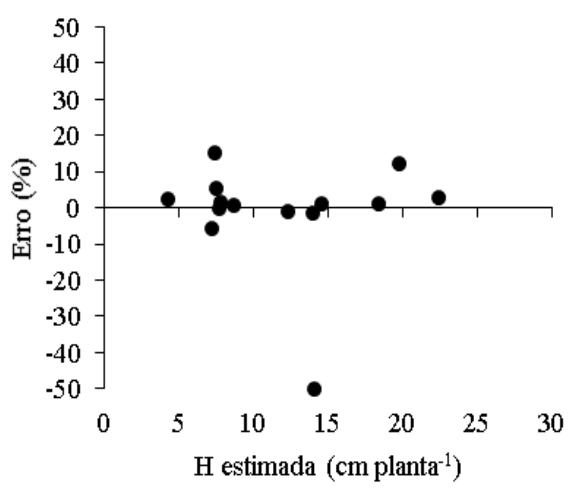

MST

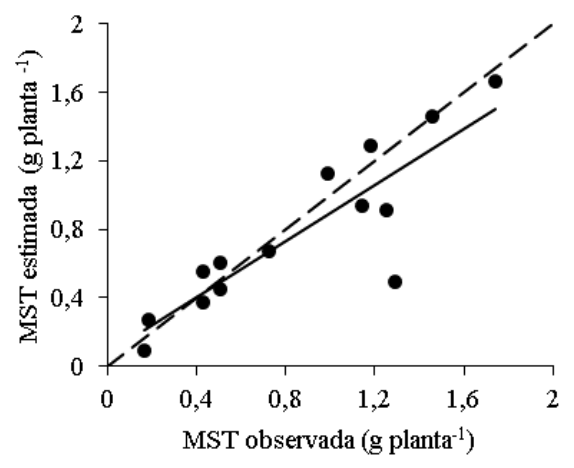

MST

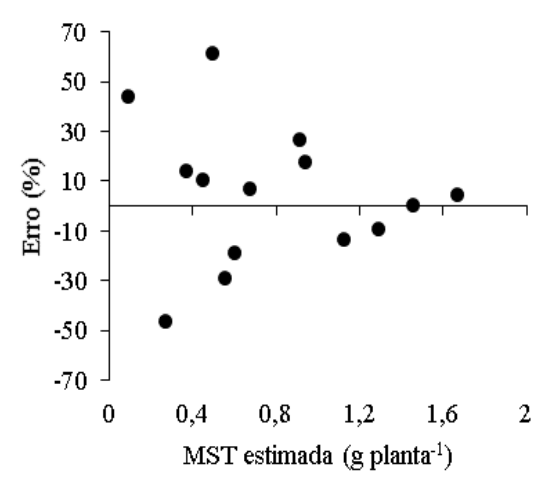

Figura 4. Altura observada e estimada, distribuição gráfica dos resíduos, massa seca observada e estimada, distribuição dos resíduos por RNA para o conjunto de treinamento e validação de mudas de Jacaranda brasiliana, Myracrodruon urundeuva e Mimosa caesalpiniaefolia.

Figure 4. Observed and estimated height, graphical distribution of residues, observed and estimated dry mass, distribution of residues by RNA for training and validation of Jacaranda brasiliana, Myracrodruon urundeuva and Mimosa caesalpiniaefolia seedlings. 
As MLP treinadas para estimar MST para as mudas nativas forneceram para o conjunto de treinamento valores de r entre 0,7585 e 0,9658; RQME de 0,1639 a 0,3406 e Viés de -0,0637 a 0,0807 (Tabela 5). Já os dados utilizados na validação forneceram valores de $r$ entre 0,7585 e 0,9658; RQME de 0,1639 a 0,3406 e Viés de $-0,0637$ a 0,0807.

No conjunto de validação os valores mais baixos de RQME foram obtidos com 10 e 11 neurônios na camada intermediária, com aumento a partir de 12 neurônios (Figura 3b). Esta mesma observação pode ser feita para os valores de $r$ quando se considera os mesmos valores de neurônios. Cabe ressaltar que, em vez de ter um aumento, ocorre uma diminuição no valor no $r$ a partir de 12 neurônios (Figura 3d). Os valores de Viés foram mais próximos de zero na MLP com 10 neurônios (Figura 3f).

Os gráficos de dispersão e os resíduos gerados a partir do treinamento e validação das $M L P$ escolhidas para estimar H e MST estão apresentados na Figura 3 e Figura 4. As escolhas das melhores MLP foram feitas com base nas melhores estatísticas de treinamento e validação (Tabela 4 e Tabela 5), e também com a melhor combinação desses valores de acordo com a variação no número de neurônios demonstrados na Figura 3. Dessa forma, os gráficos foram gerados com a MLP com 4 neurônios na camada intermediária para estimar H e 10 neurônios para estimar MST.

Os gráficos da relação entre o valor observado e estimado tanto para $\mathrm{H}$ como para MST apresentaram um comportamento linear crescente nos conjuntos de treinamento e validação. Essa relação pode ser verificada ao comparar a reta de linha pontilhada (relação perfeita) com a reta sólida (Figura 4).

Os gráficos de dispersão dos resíduos não apresentaram tendenciosidade aparente para os conjuntos de treino e validação na estimativa da $\mathrm{H}$. Já os erros referentes às estimativas de MST indicaram uma baixa tendência de subestimação da $M L P$.

Constatou-se pela análise gráfica dos resíduos (Figura 3 e Figura 4) e pelas estatísticas apresentadas (Tabela 4 e Tabela 5) para os tipos de MLP testadas, que os resultados foram satisfatórios. Resultados semelhantes foram encontrados por FERREIRA et al. (2014), que utilizou RNA para estimar altura de mudas da Tibouchina granulosa Cogn.

As RNA têm sido empregadas em substituição aos modelos de regressão convencionais, pelo fato de não precisar atender os pressupostos estatísticos como tais modelos (NUNES \& GÖRGENS 2016). Esta técnica desenvolve modelos preditivos para analisar relações complexas entre as variáveis sem precisar fazer suposições dos dados como linearidade, normalidade e colinearidade (RECKNAGEL 2001). Isto permite maior flexibilidade da RNA em verificar certas relações entre atributos florestais e proporcionam bom desempenho, como o obtido pelas redes diante da complexa relação do diâmetro com a altura das mudas sob diferentes composições de substrato (FERREIRA et al. 2014).

Diante dos resultados positivos e validados encontrados para estimação da $\mathrm{H}$ e MST de mudas de Jacaranda brasiliana, Myracrodruon urundeuva e Mimosa caesalpiniaefolia, reafirma-se que uso das RNA para avaliação da qualidade de mudas florestais é uma alternativa indiscutivelmente viável e atrativa. Dessa forma, possibilita a otimização na seleção de genótipos fotossinteticamente mais eficientes, e consequentemente maior probabilidade de sobrevivência e sucesso dos programas de restauração florestal.

Fisiologicamente, sabe-se que quanto maior a MST de mudas, maior a fixação de carbono e produção de fotoassimilados, sendo um bom indicador da assimilação líquida, e, portanto, para o crescimento futuro. No entanto, devido ainda a poucas informações desse estudo, propõe-se a avaliação da aplicabilidade e confiabilidade do uso das RNA na estimação da qualidade de mudas de outras espécies florestais.

A seleção da $M L P$ com o melhor número de neurônio na camada intermediária não é um processo trivial, por se tratar de um método aproximativo ou heurístico, normalmente feito por tentativas e erro. Alguns trabalhos reportam essa afirmação, como BINOTI et al. (2014). Os autores sugerem um número ótimo de 10 neurônios na camada intermediária. Neste trabalho o número de neurônios considerado ideal na camada intermediária para estimar a $\mathrm{H}$ foram 3 e para estimar a MST de mudas foram 10 neurônios.

\section{CONCLUSÃO}

O esterco bovino e caprino foram os resíduos orgânicos que proporcionaram o maior crescimento de mudas de Jacaranda brasiliana, Myracrodruon urundeuva e Mimosa caesalpiniaefolia.

As RNA do tipo MLP treinadas nesse trabalho forneceram resultados satisfatórios na estimativa de altura e massa seca total para as mudas de plantas Jacaranda brasiliana, Myracrodruon urundeuva e Mimosa caesalpiniaefolia. Sendo, portanto, recomendado o uso de RNA para este fim.

As MLP apresentam uma variação nas estatísticas de acordo o aumento de neurônios na camada intermediária. Por isso, é importante testar diferentes números de neurônios como avaliado neste estudo. 


\section{REFERÊNCIAS}

ARAÚJO EF et al. 2017. Crescimento e qualidade de mudas de paricá produzidas em substratos à base de resíduos orgânicos. Nativa 5: 16-23.

ASHRAF MI et al. 2015. A novel modelling approach for predicting forest growth and yield under climate change. PloS one 10: $1-18$.

BINOTI MLMS et al. 2013. Aplicação de redes neurais artificiais para estimação da altura de povoamentos equiâneos de eucalipto. Revista Árvore 37: 639-645.

BINOTI MLMS et al. 2014. Redes neurais artificiais para estimação do volume de árvores. Revista Árvore 38: $283-288$.

BINOTI MLMS et al. 2015. Prognose em nível de povoamento de clones de eucalipto empregando redes neurais artificiais. Cerne 21: 97-105.

BRAGA AP et al. 2007. Redes neurais artificiais: teoria e aplicações. 2.ed. Rio de Janeiro: LTC. 248p.

BRASIL. 2010. Política nacional de resíduos sólidos, Lei 12.305, de 2 de agosto de 2010. Institui a Política Nacional de Resíduos Sólidos. DOU 3/10/2010. Seção 1. p.3.

CABACINHA CD \& LAFETÁ BO 2017. Floristic diversity and equitability in forest fragments using artificial neural networks. Ciência Florestal 27: 143-152.

CABREIRA GV et al. 2017. Biossólido como componente de substrato para produção de mudas florestais. Floresta 47: 165-176.

CARNEIRO JGA. 1995. Produção e controle de qualidade de mudas florestais. 1.ed. Curitiba: UFPR. 451p.

CRUZ CAF et al. 2006. Efeito da adubação nitrogenada na produção de mudas de Sete-Cascas (Samanea inopinata (Harms) Ducke). Revista Árvore 30: 537-546.

CRUZ CAF et al. 2011. Efeito de macronutrientes sobre o crescimento e qualidade de mudas de canafístula cultivadas em Latossolo Vermelho-Amarelo distrófico. Revista Árvore 35: 983-995.

DONAGEMA GK et al. 2011. Manual de métodos de análise do solo. 2.ed. Rio de Janeiro: Embrapa Solos. 225p.

FERNANDES MM et al. 2014. Aspectos biológicos e espécies potenciais para restauração ecológica de áreas em desertificação no Sul do Piauí - Brasil. Revista Verde de Agroecologia e Desenvolvimento Sustentável 9: 6-13.

FERREIRA JCB et al. 2014. Altura de mudas de Tibouchina granulosa Cogn. (melastomataceae) estimada por redes neurais artificiais. Revista da Sociedade Brasileira de Arborização Urbana 9: 151-160.

GASPARIN E et al. 2014. Influência do substrato e do volume de recipiente na qualidade das mudas de Cabralea canjerana (Vell.) Mart. em viveiro e no campo. Ciência Florestal 24: 553-563.

GOMES JM \& PAIVA HN. 2012. Viveiros florestais: propagação sexuada. Viçosa: UFV. 116p.

HAYKIN S. 2001. Redes neurais: princípios e prática. 2.ed. Porto Alegre: Bookman. 900p.

LARCHER W. 2000. Ecofisiologia vegetal. 1.ed. São Carlos: RIMA Artes e Textos. 532p.

LEITE HG et al. 2011. Estimation of inside-bark diameter and heart wood diameter for Tectona grandis Linn. trees using artificial neural networks. European Journal of Forest Research 130: 263-269.

LUSTOSA FILHO JF et al. 2015. Influence of organic substrates on growth and nutrient contents of jatobá (Hymenaea stigonocarpa). African Journal of Agricultural Research 10: 2544-2552.

MAEDA EE et al. 2009. Predicting forest fire in the Brazilian Amazon using MODIS imagery and artificial neural networks. International Journal of Applied Earth Observation and Geoinformation 11: 265-272.

NUNES MH \& GÖRGENS EB. 2016. Artificial Intelligence Procedures for Tree Taper Estimation within a Complex Vegetation Mosaic in Brazil. PloS one 11: 1-16.

RECKNAGEL F. 2001. Applications of machine learning to ecological modelling. Ecological Modelling 146: $303-310$.

SILVA MLM et al. 2009. Ajuste do modelo de Schumacher e Hall e aplicação de redes neurais artificiais para estimar volume de árvores de eucalipto. Revista Árvore 33: 1133-1139. 